\title{
MICROSTRUCTURE AND SOFT MAGNETIC PROPERTIES OF Fe-Zr-(Pt)-Nb-Cu-B AMORPHOUS ALLOYS
}

This paper presents the results of investigations into the microstructure and magnetic properties of $\mathrm{Fe}_{86} \mathrm{Zr}_{7} \mathrm{Nb}_{1} \mathrm{Cu}_{1} \mathrm{~B}_{5}, \mathrm{Fe}_{82} \mathrm{Z}-$ $\mathrm{r}_{7} \mathrm{Nb}_{2} \mathrm{Cu}_{1} \mathrm{~B}_{8}$ and $\mathrm{Fe}_{81} \mathrm{Pt}_{5} \mathrm{Zr}_{7} \mathrm{Nb}_{1} \mathrm{Cu}_{1} \mathrm{~B}_{5}$ alloys. The alloys were investigated in their as-quenched state, in the form of thin ribbons with approximate dimensions as follows: width $3 \mathrm{~mm}$ and thickness $20 \mu \mathrm{m}$.

The investigations were performed utilizing Mössbauer spectrometry and X-ray diffractometry. Also, an evaluation of the low-field magnetic susceptibility and measurements of the magnetization versus temperature and magnetizing field were performed.

Keywords: amorphous alloys, Mössbauer spectroscopy, magnetic susceptibility, Curie temperature, magnetic properties

\section{Introduction}

The Fe-Zr-B-Cu amorphous alloys with high iron content comprise of a very interesting group of materials; they exhibit a selection of anomalies due to lack of long range order in their atomic structure [1-3]. Moreover, with their specific chemical composition, their Curie temperature is close to room temperature which allows for their application in magnetic refrigerators.

A rapid quenching technique facilitates the manufacture of amorphous alloys. Transition metals, such as: iron, cobalt and nickel, and elements stabilizing the amorphous structure of the alloys (boron, silicon and phosphorus) are the main components of the soft magnetic amorphous alloys [4-6].

Typically, amorphous alloys have been obtained by rapid quenching of the molten material on a rotating wheel and the resulting samples have been in the form of thin ribbons with a thickness of approximately $30 \mu \mathrm{m}$.

The magnetic properties of the amorphous alloys depend on their: chemical composition, conditions of production and thermal treatment $[7,8]$.

In this paper, the results of investigations are presented, into the magnetic properties of the following amorphous alloys in their as-quenched state: $\mathrm{Fe}_{86} \mathrm{Zr}_{7} \mathrm{Nb}_{1} \mathrm{Cu}_{1} \mathrm{~B}_{5}, \mathrm{Fe}_{82} \mathrm{Zr}_{7} \mathrm{Nb}_{2} \mathrm{Cu}_{1} \mathrm{~B}_{8}$ and $\mathrm{Fe}_{81} \mathrm{Pt}_{5} \mathrm{Zr}_{7} \mathrm{Nb}_{1} \mathrm{Cu}_{1} \mathrm{~B}_{5}$.

\section{Materials and methods}

In these investigations, amorphous alloy samples were used, in the form of ribbons of approximate width $3 \mathrm{~mm}$ and thickness $20 \mu \mathrm{m}$. Ingots of the alloys: $\mathrm{Fe}_{86} \mathrm{Zr}_{7} \mathrm{Nb}_{1} \mathrm{Cu}_{1} \mathrm{~B}_{5}, \mathrm{Fe}_{82}$
$\mathrm{Zr}_{7} \mathrm{Nb}_{2} \mathrm{Cu}_{1} \mathrm{~B}_{8}$ and $\mathrm{Fe}_{81} \mathrm{Zr}_{7} \mathrm{Pt}_{5} \mathrm{Nb}_{1} \mathrm{Cu}_{1} \mathrm{~B}_{5}$ were obtained by arc melting using high-purity elements. The amorphous ribbons were made by rapid quenching of the molten material on a single, rotating, copper wheel under a protective argon atmosphere. All measurements were performed for samples in the as-quenched state.

The microstructure and magnetic structure of the samples in the as-quenched state were investigated by means of a 'POLON' Mössbauer spectrometer, equipped with a ${ }^{57} \mathrm{Co}(\mathrm{Rh})$ source of $50 \mathrm{mCi}$ activity. Transmission Mössbauer spectra were recorded at room temperature.

Amorphicity of the investigated samples was confirmed using X-ray diffractometry. Measurements of the magnetic susceptibility were performed using a completely automated computer set-up; to facilitate this test, samples were formed into a toroidal shape, of outer diameter $2.5 \mathrm{~cm}$. The temperature ranges for the measurements of the magnetic susceptibility were chosen accordingly to the Curie temperatures of the measured alloys. In the case of the sample of $\mathrm{Fe}_{86} \mathrm{Zr}_{7} \mathrm{Nb}_{1} \mathrm{Cu}_{1} \mathrm{~B}_{5}$, the magnetic susceptibility measurements were performed over the temperature range from $160 \mathrm{~K}$ to $340 \mathrm{~K}$, for $\mathrm{Fe}_{82} \mathrm{Zr}_{7} \mathrm{Nb}_{2} \mathrm{Cu}_{1} \mathrm{~B}_{8}$, $210 \mathrm{~K}-340 \mathrm{~K}$ and for $\mathrm{Fe}_{81} \mathrm{Zr}_{7} \mathrm{Pt}_{5} \mathrm{Nb}_{1} \mathrm{Cu}_{1} \mathrm{~B}_{5}$, from $210 \mathrm{~K}$ to $360 \mathrm{~K}$. Measurements of the magnetization isothermal curves $\sigma\left(\mu_{0} \mathrm{H}\right)$ were performed using a magnetic balance [9] over the magnetic field range from 0 to $0.75 \mathrm{~T}$.

\section{Results and discussion}

The diffraction patterns for the investigated samples are presented in Fig. 1.

\footnotetext{
CZESTOCHOWA UNIVERSITY OF TECHNOLOGY, INSTITUTE OF PHYSICS, FACULTY OF PRODUCTION ENGINEERING AND MATERIALS TECHNOLOGY, 19. ARMII KRAJOWEJ AV., 42-200 CZESTOCHOWA, POLAND

** SCHOOL OF COMPUTING, ENGINEERING AND MATHEMATICS, UNIVERSITY OF BRIGHTON, LEWES ROAD, BRIGHTON BN2 4GJ, UNITED KINGDOM

\# Corresponding author: j.gondro@wp.pl
} 


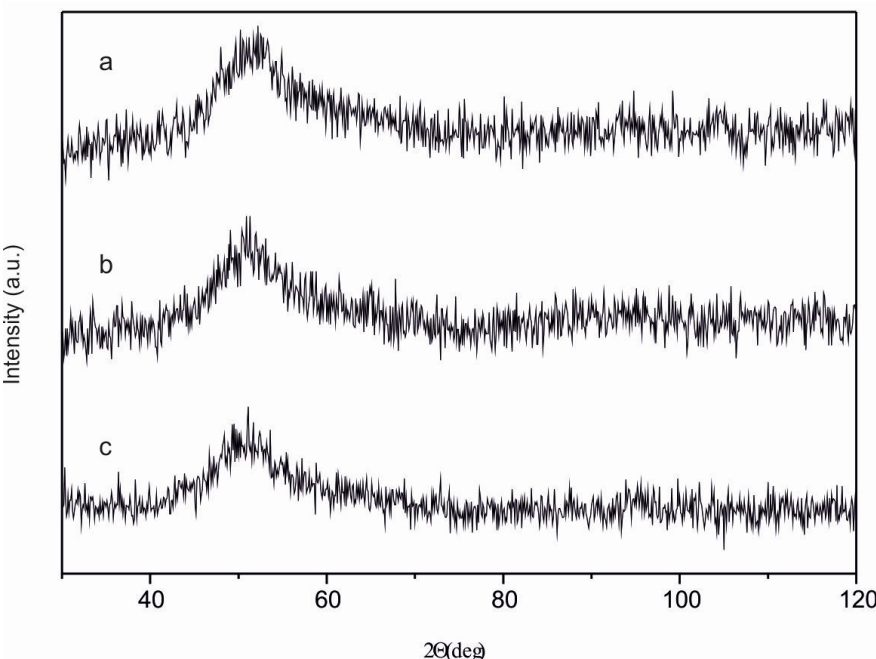

Fig. 1. X-ray diffraction patterns for the investigated samples in the as-quenched state: $\mathrm{Fe}_{86} \mathrm{Zr}_{7} \mathrm{Nb}_{1} \mathrm{Cu}_{1} \mathrm{~B}_{5}$ (a), $\mathrm{Fe}_{82} \mathrm{Zr}_{7} \mathrm{Nb}_{2} \mathrm{Cu}_{1} \mathrm{~B}_{8}$ (b), and $\mathrm{Fe}_{81} \mathrm{Zr}_{7} \mathrm{Pt}_{5} \mathrm{Nb}_{1} \mathrm{Cu}_{1} \mathrm{~B}_{5}$ (c)

The presented X-ray diffraction patterns are typical for the amorphous alloys. Only broad maxima at the $2 \Theta$ equal to $50^{\circ}$ are visible, and no narrow peaks, typical for the crystalline phase, can be distinguished. This shape of the X-ray diffraction patterns is typical for alloys which lack long-range atomic order.

The amorphicity of the investigated alloys was confirmed by transmission Mössbauer spectrometry measurements. Fig. 2 presents Transmission Mössbauer spectra (measured at room temperature) for the samples of $\mathrm{Fe}_{86} \mathrm{Zr}_{7} \mathrm{Nb}_{1} \mathrm{Cu}_{1} \mathrm{~B}_{5}, \mathrm{Fe}_{82} \mathrm{Zr}_{7}$ $\mathrm{Nb}_{2} \mathrm{Cu}_{1} \mathrm{~B}_{8}$, and $\mathrm{Fe}_{81} \mathrm{Zr}_{7} \mathrm{Pt}_{5} \mathrm{Nb}_{1} \mathrm{Cu}_{1} \mathrm{~B}_{5}$. The observed Mössbauer spectra are typical for the $\mathrm{Fe}-\mathrm{Zr}$ ferromagnetic amorphous alloys with high iron content $[10,11]$. Moreover, in the asymmetrical hyperfine field distributions, two components could be distinguished: low- and high-field. The shape of the Mössbauer spectra change after substitution of $4 \%$ of the iron atoms, $3 \%$ of the boron atoms and $1 \%$ of the niobium atoms (Fig. $2 \mathrm{c}, \mathrm{d}$ ). Data obtained from analysis of the Mössbauer spectra for the samples of the three investigated alloys, are presented in Table 1.

TABLE 1

The average magnetic induction of the hyperfine field $\left(B_{h f}\right)_{e}$, the standard deviation of the hyperfine field distribution $\left(\Delta D_{s}\right)$, and the relative intensity of the $\mathrm{A}_{2.5}$ line in the Mössbauer spectra;

brackets contain the uncertainties of the measurements

\begin{tabular}{|c|c|c|c|}
\hline \hline Alloy composition & $\left(\boldsymbol{B}_{\boldsymbol{h f}}\right)_{\boldsymbol{e f}}[\mathbf{T}]$ & $\boldsymbol{\Delta \boldsymbol { D } _ { \boldsymbol { s } } [ \mathbf { T } ]}$ & $\mathbf{A}_{\mathbf{2}, \mathbf{5}}$ \\
\hline $\mathrm{Fe}_{86} \mathrm{Zr}_{7} \mathrm{Nb}_{1} \mathrm{Cu}_{1} \mathrm{~B}_{5}$ & $4.78(2)$ & $2.55(4)$ & $1.8(3)$ \\
\hline $\mathrm{Fe}_{82} \mathrm{Zr}_{7} \mathrm{Nb}_{2} \mathrm{Cu}_{1} \mathrm{~B}_{8}$ & $9.86(2)$ & $4.17(2)$ & $2.7(1)$ \\
\hline $\mathrm{Fe}_{81} \mathrm{Zr}_{7} \mathrm{Pt}_{5} \mathrm{Nb}_{1} \mathrm{Cu}_{1} \mathrm{~B}_{5}$ & $13.12(2)$ & $4.80(2)$ & $2.77(8)$ \\
\hline
\end{tabular}

A distinct change in the Mossbauer spectra, compared with $\mathrm{Fe}_{86} \mathrm{Zr}_{7} \mathrm{Nb}_{1} \mathrm{Cu}_{1} \mathrm{~B}_{5}$ amorphous alloy, is visible for alloy in which $5 \%$ of the iron atoms have been substituted by platinum atoms (Fig. 2e,f). The spectrum obtained for this alloy is similar to that obtained for the $\mathrm{Fe}_{82} \mathrm{Zr}_{7} \mathrm{Nb}_{2} \mathrm{Cu}_{1} \mathrm{~B}_{8}$ amorphous alloy and it is typical for amorphous materials with ferromagnetic order-

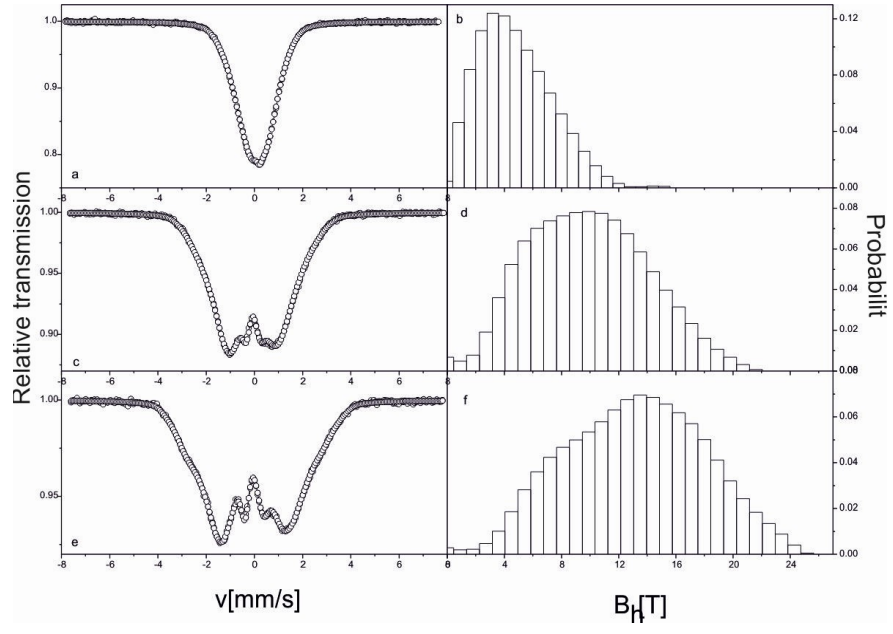

Fig. 2. Transmission Mössbauer spectra (a,c,e) and corresponding hyperfine field distributions (b,d,f) for the amorphous alloys in the as-quenched state: $\mathrm{Fe}_{86} \mathrm{Zr}_{7} \mathrm{Nb}_{1} \mathrm{Cu}_{1} \mathrm{~B}_{5}$ (a,b), $\mathrm{Fe}_{82} \mathrm{Zr}_{7} \mathrm{Nb}_{2} \mathrm{Cu}_{1} \mathrm{~B}_{8}$ (c, d) and $\mathrm{Fe}_{81} \mathrm{Zr}_{7} \mathrm{Pt}_{5} \mathrm{Nb}_{1} \mathrm{Cu}_{1} \mathrm{~B}_{5}(\mathrm{e}, \mathrm{f})$

ing. It is worth noting, that this spectrum is substantially wider than that observed for the first alloy. From the data presented in Table 1, it also could be seen that the magnetic induction of the hyperfine field is higher than for the first sample.

Magnetic susceptibility of the investigated alloys, measured as a function of temperature, in a magnetic field of amplitude $0.26 \mathrm{~A} / \mathrm{m}$ and frequency of $2 \mathrm{kHz}$, is shown in Fig. 3 .

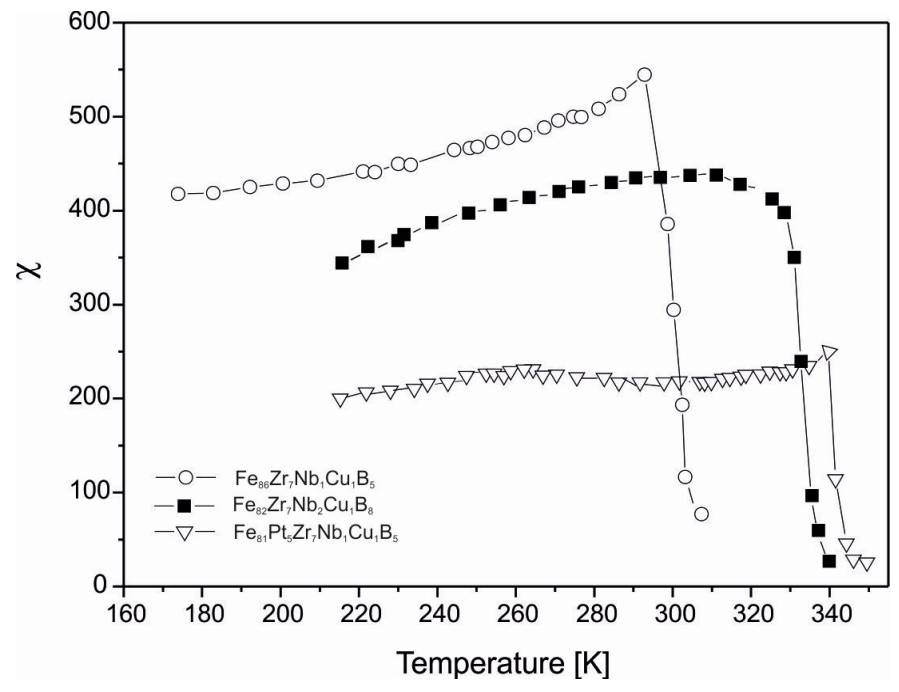

Fig. 3. The magnetic susceptibility of the investigated alloys in the as-quenched state

The magnetic susceptibility of the samples (in the asquenched state) was found to increase slightly with increasing temperature. At the temperatures of: $T=295 \mathrm{~K}, T=330 \mathrm{~K}$, and $T=340 \mathrm{~K}$, a sudden decrease in the magnetic susceptibility on the $\chi(T)$ curves can be observed. This is associated with the ferromagnetic-paramagnetic transition [12]. The maximum observed on the $\chi(T)$ curve is associated with decreases in the effective anisotropy and saturation magnetization with temperature. 
The shape of the dependency relationship of the low-field magnetic susceptibility on temperature $\chi(T)$ is similar for all three investigated alloys. However, the alloy with the addition of platinum atoms shows the highest value of Curie temperature, which is related to larger distances between iron atoms.

The Curie temperature of the investigated alloys were calculated from the magnetization curves $\sigma(T)$.

Fig. 4 shows the magnetization $(\sigma)$ for the alloys: $\mathrm{Fe}_{86}$ $\mathrm{Zr}_{7} \mathrm{Nb}_{1} \mathrm{Cu}_{1} \mathrm{~B}_{5}$ (a), $\mathrm{Fe}_{82} \mathrm{Zr}_{7} \mathrm{Nb}_{2} \mathrm{Cu}_{1} \mathrm{~B}_{8}$ (b), and $\mathrm{Fe}_{81} \mathrm{Zr}_{7} \mathrm{Pt}_{5} \mathrm{~N}$ $\mathrm{b}_{1} \mathrm{Cu}_{1} \mathrm{~B}_{5}$ (c), as a function of temperature within a constant magnetizing field of $0.75 \mathrm{~T}$.

The specific magnetization decreases monotonically with increasing temperature, but does not reach zero at a certain temperature. This is connected with inhomogeneity of the amorphous alloys, and regions featuring different Curie temperatures within the alloys. That is why, in the case of the amorphous alloys, only an average Curie temperature can be stated.

In the case of the investigated alloy samples, the Curie temperature was calculated according to a method based on analysis of the so-called critical behaviour of the magnetization in temperatures close to Curie the temperature. The value of this temperature was calculated from the linear relationship of $\sigma^{1 / \beta}(T)[13,14]$. All of the investigated alloys have a Curie temperature above room temperature. The Curie temperature of the $\mathrm{Fe}_{86} \mathrm{Zr}_{7} \mathrm{Nb}_{1} \mathrm{Cu}_{1} \mathrm{~B}_{5}$ was found to be closest to room temperature. A clear increase in the Curie temperatures has been observed after substitution of a proportion of the iron atoms in the aforementioned alloy by atoms of niobium and boron or platinum.
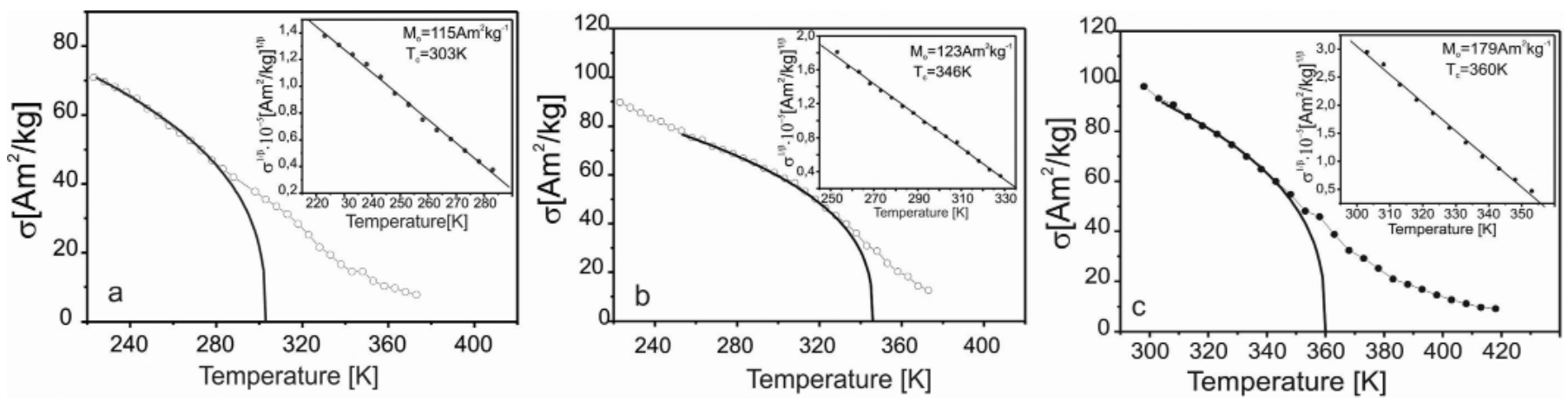

Fig. 4. Dependence of the specific magnetization $(\sigma)$ on temperature for the samples of: $\mathrm{Fe}_{86} \mathrm{Zr}_{7} \mathrm{Nb}_{1} \mathrm{Cu}_{1} \mathrm{~B}_{5}(\mathrm{a}), \mathrm{Fe}_{82} \mathrm{Zr}_{7} \mathrm{Nb}_{2} \mathrm{Cu}_{1} \mathrm{~B}_{8}(\mathrm{~b})$, and $\mathrm{Fe}_{81}$ $\mathrm{Zr}_{7} \mathrm{Pt}_{5} \mathrm{Nb}_{1} \mathrm{Cu}_{1} \mathrm{~B}_{5}$ (c) amorphous alloys in the as-quenched state. In the inset pictures, the temperature dependencies of $\left(\sigma^{1 / \beta}\right)$ are presented

Fig. 5 shows exemplary isothermal curves of the specific magnetization $\sigma\left(\mu_{0} \mathrm{H}\right)$ for the $\mathrm{Fe}_{86} \mathrm{Zr}_{7} \mathrm{Nb}_{1} \mathrm{Cu}_{1} \mathrm{~B}_{5}$ alloy in the asquenched state, for the selected temperatures (above and below the Curie temperature of the alloy $\left.T_{C}=(292 \pm 5) \mathrm{K}\right)$ within the range of magnetic induction from 0 to $0.75 \mathrm{~T}$.

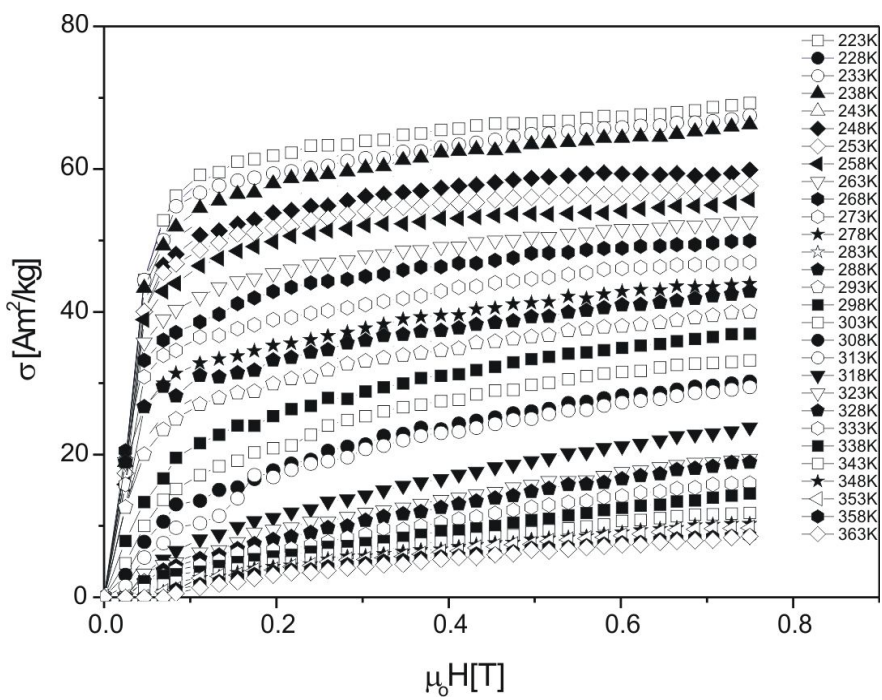

Fig. 5. Isothermal curves for the $\mathrm{Fe}_{86} \mathrm{Zr}_{7} \mathrm{Nb}_{1} \mathrm{Cu}_{1} \mathrm{~B}_{5}$ alloy in the asquenched state

The system of equations containing critical exponents makes it possible to determine the magnetic properties of fer- romagnetic materials with ferromagnetic phase transition ferroparamegnetic [15]:

$$
\begin{gathered}
M_{s}=M_{0}(-t)^{\beta} \quad \text { if } T<T_{c} \\
M=D H^{1 / \delta} \text { if } T=T_{c} \\
\chi_{0}{ }^{-1}=B t^{\gamma} \text { if } T>T_{c}
\end{gathered}
$$

where $M_{0}, D, B$ are proportionality constant, $t=\left(T-T_{c}\right) / T_{c}$, $T_{c}$ - temperature Curie. The critical exponents $\beta$ and $\gamma$ accordingly describe the temperature dependence of the spontaneous magnetization $M_{s}$ just below the Curie temperature $T<T_{C}$ and the initial permeability slightly above $T_{C}$. Exponent $\delta$ structure describes the relationship between the magnetization $M$ and the magnetizing field strength $H$ in the Curie temperature.

With isothermal magnetization curves called curves Arrota can determine the Curie temperature, the spontaneous magnetization and the initial the permeability. The appropriate selection of the exponent values of critical near the Curie temperature a pattern of parallel straight lines, which can be easily extrapolated without the use low-field data.

$$
\left(\frac{H}{\sigma}\right)^{1 / \gamma}=\frac{T-T_{c}}{T_{1}}+\left(\frac{\sigma}{M_{1}}\right)^{1 / \beta}
$$

where $T_{1}$ and $M_{1}$ are constants of dependent on the material [16] .

With increasing measurement temperature above the Curie temperature, a clear change in the shape of the curves is visible. 
This change is associated with the ferromagnetic-paramagnetic phase trasnsition. In order to distinguish the order of the phase transition, the so-called Arrott's curves have been constructed, based on the equation: $\sigma^{2}\left(\mu_{0} \mathrm{H} / \sigma\right)[17,18]$.

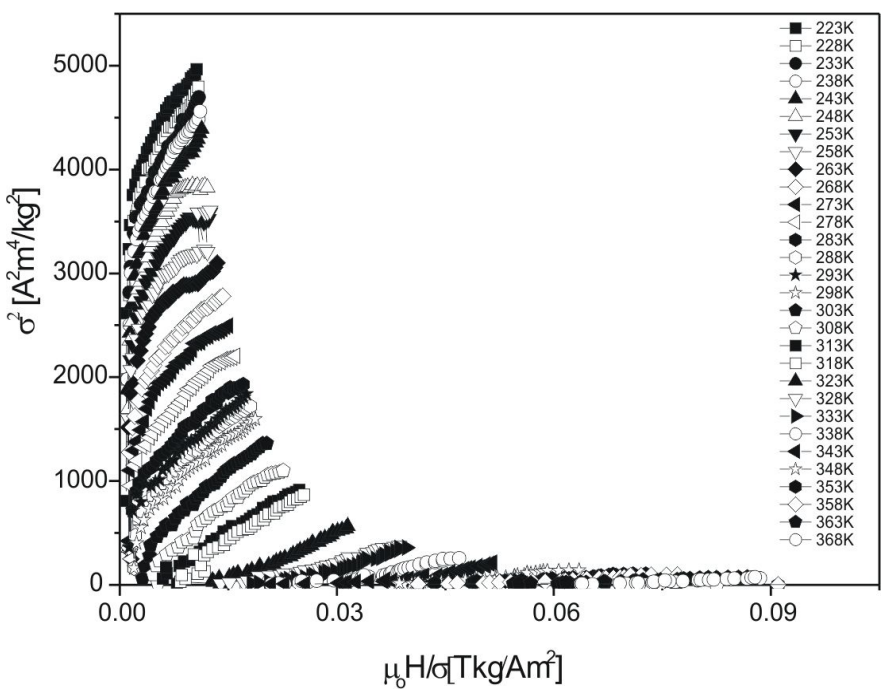

Fig. 6. The Arrott's curves: $\sigma^{2}\left(\frac{\mu_{0} H}{\sigma}\right)$ at the induction of the magnetizing field from 0 to $0.75 \mathrm{~T}$ for the $\mathrm{Fe}_{86} \mathrm{Zr}_{7} \mathrm{Nb}_{1} \mathrm{Cu}_{1} \mathrm{~B}_{5}$ alloy, after thermal treatment for 15 minutes at a temperature of $573 \mathrm{~K}$, increasing to $600 \mathrm{~K}(4 \mathrm{a})$

As can be seen in Fig. 6, the gradient of the Arrott's curves is positive at temperatures close to the Curie temperature; this is confirmation that, in the case of this alloy, the paramagnetic-ferromagnetic phase transition is a second-order phase transition [19].

Similar properties were observed for the other two investigated alloys.

\section{Conclusions}

On the basis of the performed investigations, it was found that:

- The ribbons of the $\mathrm{Fe}_{86} \mathrm{Zr}_{7} \mathrm{Nb}_{1} \mathrm{Cu}_{1} \mathrm{~B}_{5}, \mathrm{Fe}_{82} \mathrm{Zr}_{7} \mathrm{Nb}_{2} \mathrm{Cu}_{1} \mathrm{~B}_{8}$ and $\mathrm{Fe}_{81} \mathrm{Zr}_{7} \mathrm{Pt}_{5} \mathrm{Nb}_{1} \mathrm{Cu}_{1} \mathrm{~B}_{5}$ in the as-quenched state were fully amorphous;

- The investigated alloys exhibit good soft magnetic properties over a wide temperature range;
- The addition of: boron, niobium and platinum to the $\mathrm{Fe}_{86} \mathrm{Z}$ $\mathrm{r}_{7} \mathrm{Nb}_{1} \mathrm{Cu}_{1} \mathrm{~B}_{5}$ alloy resulted in an increase in the value of the average hyperfine field, which is associated with larger distances between iron atoms, due to the increase in volume caused by the boron and platinum in the alloy;

- The highest Curie temperature was observed for the alloy with the addition of the platinum;

- The paramagnetic-ferromagnetic phase transition for all of the investigated alloys is a phase transition of the second order.

\section{REFERENCES}

[1] J.M.D. Coey, Amorphous Solid and Liquid State 13, 433-466 (1985).

[2] S.N. Kaul, V. Siruguri, G. Chandra, Phys. Rev. B 45, 12343-12356 (1992).

[3] J. Gondro, J. Magn. Magn. Mater. 432, 501-506 (2017).

[4] E.F. Wassermann, Advances in Solid State Physics 27, 85-107 (1987).

[5] R. Hasegawa, J. Magn. Magn. Mater. 41, 79-85 (1984).

[6] K. Błoch, J. Magn. Magn. Mater. 390, 118-122 (2015).

[7] J. Gondro, J. Świerczek, K. Błoch, J. Zbroszczyk, W. Ciurzyńska, J. Olszewski, Physica B 445, 37-41 (2014).

[8] J. Zbroszczyk, J. Olszewski, W. Ciurzyńska, M. Nabiałek, P. Pawlik, M. Hasiak, A. Łukiewska, K. Perduta, J. Magn. Magn. Mater. 304, 2 724-726 (2006).

[9] Z. Obuszko, Acta Phys. Polon. 33, 673 (1968).

[10] R. Meyer, H. Kronmüller, Phys. Stat. Sol. B, 693-703 (1982).

[11] J. Olszewski, Hyperfine Interactions 131, 83-90 (2000).

[12] H.W. Kwon, S.W. Shon, J. Magn. 6 (2), 61-65 (2001).

[13] R. Meyer, H. Kronmüller, Phys. Stat. Sol. B 109, 693-703 (1982).

[14] S.N. Kaul, Phys. Rew. B 22, 278-287 (1980).

[15] R. Reisser, M. Seeger and H. Kronmüller, J. Magn. Magn. Mater. 128, 321-340 (1993).

[16] A. Arrott, J.E. Noakes, Phys. Rev. Lett. 19, 786-789 (1967).

[17] A.S. Arrott, J. Magn. Magn. Mater. 322, 1047-1051 (2010).

[18] J. Schneider, A. Handstein, K. Zavěta, J. Magn. Magn. Mater. 42 73-88 (1984).

[19] S.K. Banerjee, Phys. Lett. 12, 16-17 (1964). 